\title{
Foreignizing or Domesticating Tendencies in Pazargadi's English Translation of Hafez's Lyrics: Study a Case
}

\author{
Seyed Alireza Shirinzadeh \\ Faculty of Translation Studies, School of Languages, Literacies \& Translation, Universiti Sains Malaysia \\ Email: alireza.shirinzadeh@gmail.com \\ Tengku Sepora Tengku Mahadi
}

Faculty of Translation Studies, School of Languages, Literacies \& Translation, Universiti Sains Malaysia

\section{Doi:10.5901/mjss.2014.v5n20p2350}

\begin{abstract}
The present paper aims at exploring Hafez's lyrics translated into English with the purpose of identifying domesticating and foreignizing tendencies and the degree of visibility of the source text author opposing the translator in the target text. For this purpose, forty six randomly selected Hafez's lyrics have been analyzed along with their English translation by Pazargadi (2003). Then, a number of instances have been extorted from the source text translated into English, their comparison to the original has been essential to extract the translator's approach both toward the original and toward the translation readers. This study shows to what extent the source text, i.e., Hafez's lyrics, resisted cultural values of the target language or submitted to them in the course of translation.
\end{abstract}

Keywords: cultural values; domestication; foreignization; visibility

\section{Introduction}

Translation has always been an important tool for transmitting science, cultures, thoughts, and all human related issues. Thus, it is used among various nations for enriching each other thoughts, cultures, languages and so forth. From the beginning of the translation, there have been translation problems. It depends on the text type which is going to be rendered. One of the most complicated types of text is literary one, as literature has always owned its specific language for conveying the meaning of the author (Gutt, 1996). The language that carries many subtleties and many literary features like metaphors, allusions, similes and the rest. Translators of this kind of texts are dealing with all kinds of elements and the choice of choosing the proper translation for each one of them. Accordingly, a literary work is integrated with a particular cultural society; thus, it is full of references to cultural, social, linguistic and historical values (Gutt). In view of that, Gutt states that "as an instance of human communication, literary translation operates by certain laws and principles assumed to be built into our human make-up. These natural laws of communication give rise to implicit information and are responsible for its characteristics" (p. 239). This fact emphasizes the interdependence of text, its surrounding context and successful interaction between the text and its readers.

As far as meaning is concerned, Nida and Taber (1982) believe that translation deals with recreating in the target language the "closest natural equivalent of the source language message", primarily "in terms of meaning" (p. 12). They further state that translation should try to recreate the message. However, to recreate the message, the translator should apply some lexical and syntactical adjustments. This shows that the main function of translation is communicating the meaning of the source text not the form. Thus, translators should have the ability to realize the meaning of the original text. Meanings are produced not only by linguistic elements of the language, but also by extra-linguistic elements of the language (Beekman \& Callow, 1974/1986).

Accordingly, Beekman and Callow (1974/1986) believe that there are two kinds of implicit meaning: linguistic implicit meaning and cultural implicit meaning. The former deals with the implied meaning which can be traced linguistically. For example, the figures of speech that are used in a text belong to linguistic sect as they can be derived from the text. However, the latter deals with the implicit meaning that cannot be derived from the text; they are extratextual; in other words, one cannot understand them via the grammar of the language as they are out of the text (Beekman \& Callow). Therefore, the translators should pay proper attention to them as well; otherwise, they can be 
problematic as they may cause a gap of understanding for the target text readers.

Now that the issue of cultural implicit meaning has been brought up, the term culture itself should be explained; accordingly, Newmark (1988) defined culture as " the way of life and its manifestations that are peculiar to a community that uses a particular language as its means of expression"; therefore, he believes that all languages have their own culturally particular features. He further refers to cultural words which are hard to be understood by the target text readers and entail particular translation strategies to be applied by the translators. Though he states that types of these strategies depend on text type, readership, publishers and many other factors. Newmark proposes five categories for cultural words. They are as follows: a) ecology, b) material culture, c) social culture, d) organizations, customs, activities, procedures, ideas and concepts, e) gesture and habits (p. 95). Ecology includes animals, plants, local winds, mountains, plains, ice, etc. (p. 103). Material culture (artefacts) includes food, clothes, houses and towns, and transport (p. 95). Social culture includes work and leisure (p. 95). Organizations, customs, activities, procedures, ideas and concepts belong to the following types, i.e., social, political, administrative, religious and artistic ones (p. 95). Gesture and habits refer to behaviors which are particular in a specific society or among a group of people. Accordingly, "if people smiles a little when someone dies, do a slow hand-clap to express warm appreciation, ...kiss their finger tips to greet or to praise, give a thumbs-up to signal OK," all belong to particular cultures (p. 102). Besides Newmark, Pedersen (2011) also gives a category for cultural loaded words. He considers proper names of people, places, institutions, customs, food etc. as cultural loaded words (p. 44). In this study, both of these categories have been used for data collection.

There are three significant cognitive procedures in translation. They are understanding of the original text, producing the target text and exchanging between ST and TT linguistic systems (Ruiz et al., 2008; Gile, 2009; Jensen, 2011). It is important that when translating a text, the translators pay due attention to both source text (ST) and target text (TT). Sometimes, the translators allocate more time to the TT than to the ST; this is common among the professional translators (Jensen, 2011). As cultural implicit meanings lie in the original text, translators should, therefore, allocate due time for exploring the ST. Sometimes, it needs reading between the lines. More importantly, the translator should not only be an expert in the language of ST but also should know all areas around the text he is rendering, in other words, the information out of the text. Accordingly, Limon (2010) believes that Translation Studies should not just concern with translation product and process which are the linguistic parts; but, he thinks translation can work as an intercultural connector to link two societies and cultures. We believe the same that translation is in fact a bridge to connect the two perhaps entirely different worlds with dissimilar cultures and beliefs. Moreover, translators can be regarded as cultural third party who has good and to the point cultural knowledge besides being an expert in that specific topic of translation (Wilss 1999; Katan, 2004).

\section{Theoretical Background of the Study}

A crucial decision that the translators of Hafez's lyrics should make is that they should produce a translation which maintains the original Persian cultural items or they should generate a translation that is accepted in the English target cultural setting. These are the tendencies that translators may have while translating Hafez's lyrics. These tendencies have been discussed by some translation scholars and gained different labels. This section of the study will discuss these tendencies so as to prepare a theoretical background which supports the main theoretical framework of this study.

Venuti (1995) proposes domestication and foreignization strategies as two umbrella terms for discussing the strategies that the translators may use. He states that domestication is "an ethnocentric reduction of the foreign text to target language cultural values" (p. 20). He actually believes that domestication dominates the "Anglo-American translation culture" (Munday, 2001, p. 146). According to Venuti, domestication leads to obvious, smooth and "invisible" text in which the target text unconventionality and unfamiliarity have been reduced (p. 146). On the other hand, Venuti $(1995$, p. 20) states that foreignization is "an ethnodeviant pressure on values to register the linguistic and cultural difference of the foreign text, sending the reader abroad." He believes it to be "highly desirable" as it controls "the ethnocentric violence of translation" (p. 20). Munday (2001) duly paraphrases it: the strategy of foreignization is able to control the vicious domestication of cultural principles. This strategy adds to the foreignness of the translation. Venuti (1998, p. 242) states that foreignization strategy "entails choosing a foreign text and developing a translation method along lines which are excluded by dominant cultural values in the target language." He further mentions that "foreignizing translation seeks to evoke a sense of the foreignness" in the translation (p. 242). Indeed, Venuti (1991) believes that his tendency toward the foreignization strategy goes along with Schleiermacher's belief. In fact, Schleiermacher believes that a translation should have foreign features and this kind of translation is better than a naturalized rendition of a text (cited by Venuti, 1991). Having the same view (supporting foreignization in translation), Berman honors Schleiermacher's early nineteenth century fundamental critique of the domesticating tradition and thinks highly of foreignization in translation 
(cited by Venuti, 2000). Accordingly, Venuti (1991) also believes in foreignizing the text so as to stand against the longstanding tradition of domesticating the translation which has dominated "Anglo-American and French culture" (p. 150). Indeed, Venuti's support of foreignization strategies of translation has not just remained in theory for himself. He (1996) states that in a project of translating Tarchetti's tale, he has followed the foreignized strategies. "My version in fact follows the Italian quite closely, often resorting to calque renderings" of the original terms (p. 97). According to Pedersen's (2011) taxonomy, calque belongs to the direct translation strategy which is itself a source-oriented strategy. And source-oriented strategies belong to the foreignization category. Venuti (1996) continues to say that his willingness toward foreignization comes from "a political agenda that is broadly democratic:" a disagreement with the worldwide English dominance (p. 92). He believes that the American dominance whether politically or fanatically has moved other 'languages and cultures' to marginal sides with respect to its 'language and culture'. According to Venuti (1995), translators should first choose the foreign work for translation, and then, use the proper strategies to translate it. There are basically two categories for the strategies that the translators use, namely, foreignizing and domesticating strategies (Venuti). In fact, scholars have used different labels for these two categories; but, they are following the same views. In line with this, Schleiermacher states that translators have two choices: "either the translator leaves the writer alone as much as possible and moves the reader toward the writer, or he leaves the reader alone as much as possible and moves the writer toward the reader" (cited by Snell-Hornby, 1988, p. 145). He believes in the first choice and persuades translators to avoid keeping the readers at home in their recognized environment. These two choices are called domestication and foreignization by Venuti.

In line with Venuti, Oittinen (2006, p. 42) distinguishes these two strategies and states "while domestication assimilates text to target linguistic and cultural values, in foreignization, some significant traces of the original text are retained." However, other scholars have proposed their own opinions about this issue. Yang (2010) discusses different scholars' ideas regarding foreignization and domestication. He highlights scholars like Xu who brings up the topic of competition of cultures and believes that translators should employ the target language potentials to make the translation fine-looking. In fact, the way Xu (2000) insists on eastern culture and literature in comparison with the western ones can make $\mathrm{Xu}$ one of the advocates of the French tradition of using domesticated strategies. In contrast with $\mathrm{Xu}$ and in line with Venuti and the whole German tradition of foreignization, Tan (2009) believes that "Human wisdom belongs to the entire human race. Why should artificial barriers be set up to prevent it from spreading across social, cultural, ethnological and geopolitical borders?" (p. 300). Tan further mentions that nothing is wrong with rendering valuable foreign works to Chinese with preserving the sense of foreignness in the translation. Tan states that the previous decades that have passed after the Cultural Revolution of China revealed that using alien and unfamiliar beliefs has added "new blood into the age-old Chinese tradition of theoretical thinking about translation" (p. 300); therefore, we can use foreignized strategies as well. However, now, we have a new trend. Currently, scholars in Translation Studies believe in an existing continuum for these two extreme strategies in which pure domestication and pure foreignization are the two poles (Ramiere, 2006; Pedersen, 2007; Judickaitè, 2009). So, we have an extremely domesticated strategy and an extremely foreignized one and strategies that lie between these two poles in the continuum. They believe that text type and readers and other factors will affect the strategies that the translator may use. And, these strategies may vary across the continuum.

In fact, the important point here is that translators always decide which strategy to use which one not to use; however, they have to bear this in mind that no matter what strategies they apply, there should be consistency in their choices, particularly, when they want to avoid ambiguities for the target text readers and have a smooth stream of understanding.

\section{Method}

Hafez's lyrics have been used as the source text of this study. Hafez is a well-known Persian poet whose lyrics have been translated into different languages such as German, French and English by different translators. The present study explores the translation of cultural loaded words of Hafez's Lyrics. Pazargadi's (2003) English translation has been used in this study. The reason of choosing this English translation as the target text of the present study is that Dr. Pazargadi, besides being a translator, was a poet himself; furthermore, his translations are mostly from literary works; therefore, he can be regarded as a professional literary translator. Among his translations of literary works from Persian into English or the opposite, we can name English translations of Sa'di's Bustan and Hafez's lyrics, and Persian translation of Shakespeare's works; thus, he was quite familiar with the literary genre which caused his English rendition of Hafez's lyrics to be quite outstanding. For the purpose of performing the current research, forty six lyrics of Hafez have been selected randomly to be analyzed. This study is a descriptive one which aims to investigate the existing norm in the product of the translation (Holmes, 1988). Firstly, the researchers have extracted the cultural loaded elements from the 
source text; then, they have explored their translation to see what the translator did in terms of their translation into English and whether his prevailing tendency is toward domesticated or foreignized procedures.

For analyzing the translation of the cultural loaded words of Hafez's lyrics, the categorization proposed by Ramiere (2006) has been applied. For this purpose, the items that have been identified in the source text, i.e., Hafez's lyrics have been compared with their translation so as to extract the procedures that the translator has used. Then, they have been put under each category. The category has been discussed in the following section.

\subsection{Theoretical framework}

In her study, Ramiere (2006) proposes a classification for procedures which are applied in translating cultural loaded words. She suggests a continuum for foreignization and domestication procedures. Foreignization and domestication are the two poles of the continuum. According to Ramiere, there are six procedures across the continuum. They are borrowing, calque, gloss, omission, neutralization, and cultural substitution (p. 156). This classification can be seen in the following figure.

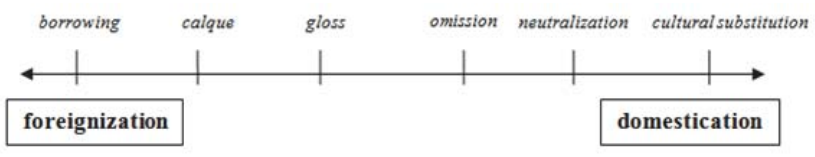

Figure 1. Translation Procedures for Rendering Cultural loaded Words Adopted from Ramiere (2006)

\subsubsection{Borrowing}

When the translator transfers the source text term in the target text without any changes or just with some spelling or phonetic changes, he uses the borrowing procedure (Ramiere, 2006). It is considered as the most foreignized procedure, since the source text item is transported to the target text. For example, the Persian word [ræmezän] is borrowed in English as Ramazan.

\subsubsection{Calque}

Calque is a translation procedure in which the translator translates the source text item literally (Ramiere, 2006). This procedure will bring about strangeness for the target text readers. In fact, by using this procedure, the translator has used literal translation in the target text. For instance, the English terms Conservative Party and Labour Party, which are literally translated into Persian as [hezbe mohäfezekär] and [hezbe kärgær] respectively.

\subsubsection{Gloss}

This procedure is used when the translator uses some explanations in translating the source text item (Ramiere, 2006). The explanation can be used in the body of the text or outside of the main body in terms of a footnote or a gloss. According to Ivir (1987, p. 38), the explanation aims at "reducing the unknown to the known and the unshared to the shared"; in fact, it tries to decrease the ambiguities that the translation readers may have regarding the translated item. For example, in translating the Persian word [noruz], the translator may use the following explanation as a footnote: a historical ceremony of the Iranian new year. It has to be mentioned that in the present study, this procedure may be used simultaneously with other procedures specially with borrowing procedure where the translator borrows the item in the translation and adds an explanation as marginal notes so as to accommodate the information that the readers may need. In this study, we also consider cases of paraphrasing and descriptive substitute of the source text item under this section.

\subsubsection{Omission}

When the translator removes the source text item in the target text, he uses the omission procedure (Ramiere, 2006). It may occur owing to different reasons; for instance, when the translator thinks that removing the original item does not harm the target text, he may omit the item. However, it is normally used as the last resort when the source text item 
cannot be translated into the target text with other procedures. In the present study, items that are partly omitted are also regarded as omission procedure. For example, the Persian noun [roknäbäd] may be translated into English as Rokn where it is partly borrowed and partly omitted.

\subsubsection{Neutralization}

When a cultural loaded word in the source text is substituted with another word in the target text which is not cultural anymore, the translator uses the neutralization procedure (Ramiere, 2006). Indeed, he neutralizes the item in the translation. In the present study, using a super-ordinate term is also regarded as neutralization. For example, the Indian new year Diwali is translated into Persian as [säle no] (new year). In this case, the translator uses a neutralized term instead of a cultural word. Another example, which can be mentioned here, is Eskimo's words for different kinds of snow which are culture specific, e.g., Qanikcaq, Nutaryuk, and Qanisqineq (Jacobson, 2012). However, they may be neutralized while translating into Persian. The translator may substitute them with the Persian word [bærf] (snow) which is a super-ordinate term.

\subsubsection{Cultural substitution}

The translator uses the cultural substitution procedure when he substitutes a cultural item in the source text with another cultural item in the target text, but with similar or near function (Ramiere, 2006). This procedure is the most domesticated procedure in which there is no sense of foreignness to the readers. For example, when the Persian word [masjed] (mosque) is substituted with the English word church, the cultural substitution procedure has been used. In the present study, substituting the source text cases with their conventional forms in the target text are also regarded as the cultural substitution procedure. In other words, if a translator uses the conventional target language form of the source text item in his translation, then the procedure will be put under this section. For instance, a translator may use the conventional English name Jesus for the Persian word [eesä] in his translation; in this case, he has used the cultural substitution procedure.

\section{Data Analysis}

In the following, only some instances of the extracted data have been given and analyzed owing to space limitation. However, the results discussed later are related to the whole extracted instances.

\subsection{Borrowing}

\begin{tabular}{|c|l|}
\multicolumn{1}{|c|}{ Example 1 } \\
\hline ST & \multicolumn{1}{c|}{ TT } \\
\hline [ke] [rizeæsh] [sære] [kæsrä] [væ] [täje] [pærviz] [æst] & $\begin{array}{l}\text { the small particles of which are Kasra's head and Parviz's crown } \\
{ }^{*} \text { These are the names of two great Sassanid kings of Iran. }\end{array}$ \\
\hline
\end{tabular}

As can be seen in this instance, the translator has borrowed the cultural loaded Persian personal names Kasra and Parviz in his English translation and has given additional information regarding them that they were two kings of Sassanian era so as to give their readers more information and bring them a better understanding of the text. The procedure that the translator has used, i.e. borrowing plus gloss, can be regarded as a foreignization procedure.

\section{Example 2}

\begin{tabular}{|l|l|}
\hline \multicolumn{1}{|c|}{ ST } & \multicolumn{1}{c|}{ TT } \\
\hline $\begin{array}{l}\text { [ærägh] [væ] [färs] [gerefti] [be] [she're] [khosh] } \\
\text { [häfez] [biä] [ke] [nobæte] [bæghdäd] [væ] }\end{array}$ & $\begin{array}{l}\text { O Hafez, you charmed Iraq and Fars beautifully by your poems; } \\
\text { come now, since it is the turn of Baghdad and Tabriz* } \\
\text { [væghte] [tæbriz] [æst] }\end{array}$ \\
$\begin{array}{l}\text { *Fars is a province in the south of Iran, and Tabriz is a city in the } \\
\text { province of Azarbayjan, in the north-west of Iran. }\end{array}$
\end{tabular}

The translator has borrowed the geographical names, namely, Fars, Baghdad and Tabriz. However, he has only used the gloss procedure for Fars and Tabriz, which are a province and a city respectively. The act of borrowing is a pure foreignization procedure as the translator has just preserved the ST item in the TT; By using the gloss, the translator is 
trying to familiarize the TT readers with ST items. Therefore, there is still the sense of the foreignness in the target text.

\subsection{Calque}

Example 1

\begin{tabular}{|c|c|}
\hline ST & TT \\
\hline [omretän] [bäd] [væ] [moräd] [ey] [säghiyän] [bæzm] [jæm] & May your life be long and happy, O cup-bearers of Jam's feast. \\
\hline
\end{tabular}

In this instance, the translator has used the calque procedure for translating the source text term, i.e., [säghiyän] where he has literally translated it to cup-bearers.

\section{Example 2}

\begin{tabular}{|l|l|}
\hline \multicolumn{1}{|c|}{ ST } & \multicolumn{1}{|c|}{ TT } \\
\hline $\begin{array}{l}\text { [hosh] [där] [ke] [gær] [væsvæseye] [æghl] [koni] [goosh] } \\
\text { [ädæm] [sefæt] [æz] [rozeye] [rezvän] [be] [dær] [äyi] }\end{array}$ & $\begin{array}{l}\text { Be alert, for, if you follow the temptation of reason, like Adam, } \\
\text { you will be expelled from the heavenly garden. }\end{array}$ \\
\hline
\end{tabular}

In the above mentioned example, the translator has translated the cultural loaded Persian phrase [rozeye] [rezvän] into English literally (the heavenly garden).

\subsection{Gloss}

\section{Example 1}

\begin{tabular}{|c|c|}
\hline ST & TT \\
\hline [bäre] [dele] [mæjnoon] [væ] [khæme] [torreye] [leili] & $\begin{array}{c}\text { The load on Majnoon's heart, and curl of Leyli's tress. } \\
\text { *The names of two legendary lovers in Persian literature. }\end{array}$ \\
\hline
\end{tabular}

In this example, the translator has transferred the Persian names, i.e., Majnoon and Leyli; it should be mentioned that they are fictional names. As can be seen, the translator has given extra information regarding them by referring that they are mythical lovers in the Persian literature which is extra-textual information as it refers to the information out of the present text. Here, the translator has applied the gloss which is a foreignized procedure.

\section{Example 2}

\begin{tabular}{|l|l|}
\hline \multicolumn{1}{|c|}{ ST } & \multicolumn{1}{|c|}{ TT } \\
\hline $\begin{array}{l}\text { [ätæshe] [toor] [kojä] [mooede] [didär] } \\
\text { [kojäst] }\end{array}$ & $\begin{array}{l}\text { where is the flame of Toor*, and where is the meeting spot? } \\
\text { *This refers to the mountain of Toor in which Moses noticed the holy flame from } \\
\text { afar. }\end{array}$ \\
\hline
\end{tabular}

In the above case, the translator has borrowed the geographical name, Toor. Moreover, he has also applied the gloss procedure by inserting an additional explanation about the term. It has been mentioned that it is the name of a mountain in the time of the prophet Moses. He has also referred to the story about it.

\subsection{Omission}

Example 1

\begin{tabular}{|c|c|}
\hline ST & TT \\
\hline [dær] [de] [be] [yäde] [hätæme] [tä'i] [jäme] [yek] [mæni] & Come and in memory of Hatam offer a full cup of wine. \\
\hline
\end{tabular}

As can be seen, the translator has omitted part of the cultural loaded Persian noun, that is, [tä'i] in the translation.

\section{Example 2}

\begin{tabular}{|c|l|}
\hline ST & \multicolumn{1}{c|}{ TT } \\
\hline [ægær] [che] [zenderood] [äbe] [hæyätæst] & Though it has a lively Zende as water of life \\
\hline
\end{tabular}

In the above example, the translator has omitted part of the Persian cultural loaded word [Zende rood] and borrowed Zende. In fact, this is the name of a river in Esfehan, a city in Iran. 


\subsection{Neutralization}

Example 1

\begin{tabular}{|c|c|}
\hline \multicolumn{1}{|c|}{ ST } & TT \\
\hline [sobh] [æst] [væ] [zhäle] [michekæd] [æz] [æbre] [bæhmæni] & It is morning and dew drips from the winter cloud; \\
\hline
\end{tabular}

In the above example, it can be seen that the Persian cultural loaded word, [bæhmæni], which is the name of a month of the winter season has been neutralized in the target text by the translator. He has used the neutralized word winter for it. Thus, he has applied the neutralization procedure.

\section{Example 2}

\begin{tabular}{|l|l|}
\hline \multicolumn{1}{|c|}{ ST } & \multicolumn{1}{|c|}{ TT } \\
\hline $\begin{array}{l}\text { [bäghe] [behesht] [væ] [säyeye] [toobä] [væ] [ghæsr] [væ] } \\
\text { [hoor] [bä] [khäke] [kooye] [doost] [bæräbær] } \\
\text { [nemikonæm] }\end{array}$ & $\begin{array}{l}\text { I refuse to regard heavenly garden, shelter of its trees, and palace } \\
\text { of houris as an equivalent of the dust of the beloved's street. }\end{array}$ \\
\hline
\end{tabular}

In the given instance, the source text cultural loaded word [toobä], has been neutralized in translation by the translator. He has substituted it with the English word trees. In fact, in the Persian culture, it is the name of a very famous tree in paradise. The target language does not have this cultural word so the translator has applied the neutralization procedure for translating it into English.

\subsection{Cultural substitution}

\section{Example 1}

\begin{tabular}{|l|l|}
\hline \multicolumn{1}{|c|}{ ST } & \multicolumn{1}{c|}{ TT } \\
\hline $\begin{array}{l}\text { [færghæst] [ze] [äbe] [khezr] [ke] } \\
\text { [zolæmät] [jäye] [oost] ... }\end{array}$ & $\begin{array}{l}\text { There is a difference between the water of Elias }{ }^{*} \text { whose place is darkness... } \\
\text { *This refers to the story of the prophet Elias (Khezr in Persian) who is said to have } \\
\text { drunk the water of eternal life in a dark cave. }\end{array}$ \\
\hline
\end{tabular}

In the above instance, the translator has used an English counterpart, Elias, for the Persian proper name, i.e., Khezr, it can be regarded as the cultural substitution which is a purely domesticated procedure. Moreover, he has also applied the gloss procedure and given additional information regarding the proper name, from outside of the text where he refers to prophet Elias and the story that he has drunk the immortalizer water. This is the information that the ST readers are familiar with and it has been mentioned here for increasing the TT readers intelligibility.

\section{Example 2}

\begin{tabular}{|l|l|}
\hline \multicolumn{1}{|c|}{ ST } & \multicolumn{1}{|c|}{ TT } \\
\hline $\begin{array}{l}\text { [hezär] [yoosofe] [mesri] [fotäde] } \\
\text { [dær] [chähe] [mäst] }\end{array}$ & $\begin{array}{l}\text { "A thousand Egyptian Josephs*have fallen in the pit of ours." } \\
\text { *This refers to the story of the prophet Joseph, son of the prophet Jacob, who was } \\
\text { imprisoned by the Pharaoh for a time. }\end{array}$ \\
\hline
\end{tabular}

In this example, the translator has used an English counterpart, Joseph, for the Persian proper name, yoosof; in fact, he has used the cultural substitution which is a domestication procedure. However, at the same time, he has inserted extra information by telling his readers that the original author is referring to the story about the prophet Joseph. This act of explicating the implicit extra-textual information is a foreignization procedure which is put under the gloss section. Moreover, for the Persian word [mesri], he has used the English conventional form, that is, Egyptian. This is also considered as the cultural substitution procedure.

Applying Venuti's (1991) notion of foreignization and domestication, the above mentioned procedures proposed by Ramiere (2006) can be classified in the following table.

Table 1. Procedures for Translating Cultural Loaded Words

\begin{tabular}{|l|l|}
\hline Foreignization & Domestication \\
\hline borrowing & cultural substitution \\
\hline calque & neutralization \\
\hline gloss & omission \\
\hline
\end{tabular}




\section{Analysis of Findings}

In this study, the cultural loaded words of the corpus of the study have been extracted. For calculating the frequency of the applied procedures and as its result, for identifying the translator's tendency toward foreignization or domestication, the gathered data should be analyzed. Totally, 113 cultural loaded words have been identified in the source text by the researchers. The procedures applied by the translator, Pazargadi, for rendering these cultural loaded words into English can be seen in Table 2.

Table 2. Translation Procedures Used by Pazargadi

\begin{tabular}{|c|c|c|c|c|}
\hline & & & Frequency & Percentage \\
\hline \multirow{8}{*}{ Tendency } & \multirow{4}{*}{ Foreignization } & Borrowing & 39 & $34 \%$ \\
\hline & & Calque & 15 & $13 \%$ \\
\hline & & Gloss & 29 & $26 \%$ \\
\hline & & Total & 83 & $73 \%$ \\
\hline & \multirow{4}{*}{ Domestication } & Omission & 3 & $3 \%$ \\
\hline & & Neutralization & 6 & $5 \%$ \\
\hline & & Cultural substitution & 21 & $19 \%$ \\
\hline & & Total & 30 & $27 \%$ \\
\hline
\end{tabular}

As can be seen, the translator has used the borrowing procedure $34 \%$. The calque procedure has been used $13 \%$. And, the gloss procedure has been applied $26 \%$. The table shows that foreignizing procedures have been applied $73 \%$ totally. As far as domestication procedures are concerned, the omission procedure has been used $3 \%$. The translator has applied the neutralization procedure $5 \%$. And, the cultural substitution procedure has been used $19 \%$. Domestication procedures have been applied $27 \%$ totally by the translator. Accordingly, the above table shows that the most frequently used procedures belong to the foreignization category with $73 \%$. In fact, the translator has opted to preserve the foreign sense in the target text.

\section{Conclusion}

The present study has attempted to find what the translator of Hafez's lyrics has done regarding the cultural loaded words and whether he has used foreignizing or domesticating procedures in his English translation. This study has shown that the source text, Hafez's lyrics, is rich in cultural loaded words. The researchers have compared the source and target texts and have categorized the extracted procedures for translating these cultural loaded elements under Venuti's dichotomy of foreignization and domestication. The results of the data analysis have revealed that the overall tendency of the translator, i.e. Pazargadi, has been toward applying the foreignization procedures in translating the cultural loaded elements of Hafez's lyrics though he has sometimes used the domestication procedures which have been $27 \%$ of the total. It has been also found that the translator's tendency is much in line with what Venuti $(1991 ; 1995 ; 1996)$ states: the idea that domestication in translation lessens the foreign culture significance. Knowing the significance of Hafez's lyrics, Pazargadi has attempted to move his translation readers toward the original author's beliefs. In fact, Pazargadi, having followed the German tradition of foreignization, has broken the dominance of Anglo-American tradition of pure domestication in his translation. Accordingly, the dominant tendency observed in the applying procedures by him is toward conveying the foreignness sense to the translation, as he has felt the importance of the source text work and its author, Hafez, which makes it almost essential for the source text to be visible in the translation. Although the translator's attitude has been toward the original author by putting him in rest at home and moving the readers abroad, he has also thought about the translation readers; whenever he has felt there are any ambiguities, he has attempted to remove them by explicating the extra hidden information.

\section{References}

Beekman, J., \& Callow, J. (1974/1986). Translating the word of God. Dallas: Summer Institute of Linguistics.

Gile, D. (2009). Basic concepts and models for interpreter and translator training. Amsterdam/Philadelphia: John Benjamins Publishing Company.

Gutt, E. (1996). Implicit information in literary translation: A relevance-theoretic perspective. Target: International Journal of Translation Studies, 8(2): 239-256. DOI: 10.1075/target.8.2.03gut

Holmes, J. (1988). The name and nature of translation studies. In J. Holmes (Ed.), Translated! Papers on literary translation and 
translation studies. With an introduction by Raymond Van den Broeck (pp. 67-80). Amsterdam/Atlanta, GA: Rodopi.

Jacobson, S. A. (2012). Yup'ik Eskimo dictionary (2nd ed.). Fairbanks, AK: Alaska Native Language Center.

Jensen, K. T. H. (2011). Distribution of attention between source text and target text during translation. In S. O'Brien (Ed.), Cognitive exploration of translation (pp. 215-237). London/New York: Continuum International Publishing Group.

Judickaitè, L. (2009). The notions of foreignization and domestication applied to film translation: Analysis of subtitles in cartoon ratatouille. JAUNŲJŲ MOKSLININKŲ DARBAI, 2(23): 36-43.

Katan, D. (2004). Translating cultures. An introduction for translators, interpreters and mediators (2nd ed.). Manchester: St Jerome.

Limon, D. (2010). Translators as cultural mediators: Wish or reality? A question for translation studies. In D. Gile, G. Hansen, \& N. Pokorn (Eds.), Why translation studies matters (pp. 29-40). Amsterdam/Philadelphia: John Benjamins Publishing Company.

Munday, J. (2001). Introducing translation studies. London/New York: Routledge.

Newmark, P. (1988). A text book of translation. London: Prentice Hall.

Nida, E. A., \& Taber, C. R. (1982). The theory and practice of translation. Leiden: Brill.

Oittinen, R. (2006). No innocent act: On the ethics of translating for children. In J. Van Coillie, \& W. P. Verschueuren (Eds.), Children's literature in translations: challenges and strategies (pp. 35-46). Manchester/Kinderhook: St. Jerome.

Pazargadi, A. (2003). The poems of Khaje Hafez Shirazi. Tehran: Rahnama Publication.

Pedersen, J. (2007). Cultural interchangeability: The effects of substituting cultural references in subtitling. Perspective: Studies in Translatology, 15(1): 30-48. DOI: 10.2167/pst003.0

Pedersen, J. (2011). Subtitling norms for television. An exploration focusing on extralinguistic cultural references. Amesterdam/Philadelphia: John Benjamins Publishing Company.

Ramiere, N. (2006, July). Reaching a foreign audience: Cultural transfer in audiovisual translation. The Journal of Specialised Translation, (6): 152-266.

Ruiz, C., Paredes, N., Macizo, P., \& Bajo, M. T. (2008). Activation of lexical and syntactic target language properties in translation. Acta Psychologica, 128(3): 490-500.

Snell-Hornby, M. (1988). Translation studies: An integrated approach. Amsterdam/Philadelphia: John Benjamins Publishing Company.

Tan, Z. (2009). The 'Chineseness' vs. 'non-Chineseness' of Chinese translation theory. The Translator, 15(2): 283-304. DOI: 10.1080/13556509.2009.10799282

Venuti, L. (1991). Genealogies of translation theory: Schleiermacher. TTR: traduction, terminologie, rédaction, 4(2): 125-150. DOI: 10.7202/037096ar

Venuti, L. (1995). The translator's invisibility. London/New York: Routledge.

Venuti, L. (1996). Translation, heterogeneity, linguistic. TTR: traduction, terminologie, rédaction, 9(1): 91-115. DOI: 10.7202/037240ar

Venuti, L. (1998). Strategies of translation. In M. Baker (Ed.), Routledge encyclopedia of translation studies (pp. 240-244). London/New York: Routledge.

Venuti, L. (2000). The translation studies reader. New York: Routledge.

Wilss, W. (1999). Translation and interpreting in the 20th century: Focus on German. Amsterdam/Philadelphia: John Benjamins Publishing Company.

$\mathrm{Xu}, \mathrm{Y} .(2000)$. New approaches to translation in the new century. Chinese Translators Journal, 2: 2-6.

Yang, W. (2010). Brief study on domestication and foreignization in translation. Language teaching and research, 1(1): 77-80. DOI: 10.4304/jtr.1.1.77-80 